\title{
Perceptions of landscape patterns: Do the numbers count?
}

\author{
by Robert G. D'Eon ${ }^{1,2}$ and Susan M. Glenn ${ }^{2}$
}

\begin{abstract}
Human perception and intuition can powerfully influence how we measure and interpret landscape pattern. We compared human perception with more quantitative measures to determine their relative efficacy in arriving at conclusions about landscape pattern. We surveyed 30 professional workshop participants and 38 undergraduate students for their perception of landscape fragmentation before and after calculating a suite of landscape metrics. Participants' perception of fragmentation was most correlated with number of patches, patch density, and patch shape. Most participants retained their original intuitive response after calculating indices. We suggest that a lack of meaningful quantitative expressions for absolute landscape structure will continue to result in a dependence on intuitive human perception for management of landscape pattern.
\end{abstract}

Key words: landscape pattern, forest fragmentation, perception, landscape metrics, forest management

La perception et l'intuition humaine peuvent exercer une influence déterminante sur notre façon de mesurer et d'interpréter le motif des paysages. Nous avons comparé la perception humaine par rapport à des mesures plus quantitatives afin de déterminer leur efficacité relative à établir des conclusions sur le motif des paysages. Nous avons étudié chez 30 participants d'un atelier professionnel et chez 38 étudiants de niveau universitaire, la perception de la fragmentation du paysage avant et après avoir calculé une série de paramètres sur les paysages. La perception des participants relativement à la fragmentation était plus en corrélation avec le nombre, la densité et la forme des trouées. La plupart des participants ont maintenu leur réponse intuitive initiale après avoir calculé les paramètres. Nous suggérons que l'absence d'expressions quantitatives significatives pour la structure globale du paysage continuera d'entraîner la dépendance envers la perception intuitive humaine dans le cas de l'aménagement du motif des paysages.

Mots-clés: motif des paysages, fragmentation forestière, perception, paramètres du paysages, aménagement forestier

\section{Introduction}

A landscape can be defined as a mosaic where the mix of local ecosystems or land uses is repeated in similar form over a kilometres-wide area (Forman 1997). With the advent of tools such as geographic information systems and satellite imagery, viewing landscapes over broad scales has become commonplace. Typically, people believe a landscape should look a certain way without questioning the necessity of that appearance (Nassauer 1988). Humans tend to construct and manage landscapes by making decisions based on what they see and know (Nassauer 1995a,b). Hundreds of quantitative measures of landscape pattern have been proposed (Gustafson 1998). However, accepted quantitative definitions of central concepts in landscape ecology such as forest fragmentation and landscape connectivity remain elusive (Hulshoff 1995, Schumaker 1996, Davidson 1998, Hargis et al. 1998).

In this paper we address human perception of landscape spatial pattern in comparison to more quantitative expressions. We specifically focus on the question: are landscape indices more useful in arriving at conclusions of acceptable accuracy to the user, than intuitive human perception in classifying landscape spatial pattern?

\section{Methods}

Thirty resource professionals were enrolled in a threehour landscape metrics workshop at an ecosystem management conference in Nelson, British Columbia, 26-28 October,

\footnotetext{
${ }^{1}$ Kokanee Forests Consulting Ltd., Box 36, Slocan, BC V0G 2C0. E-mail: rdeon@kgis.com.

${ }^{2}$ Centre for Applied Conservation Biology, Forest Sciences Department, University of British Columbia, 2424 Main Mall, Vancouver, BC V6T 1 Z4.

E-mail: sglenn@interchange.ubc.ca.
}

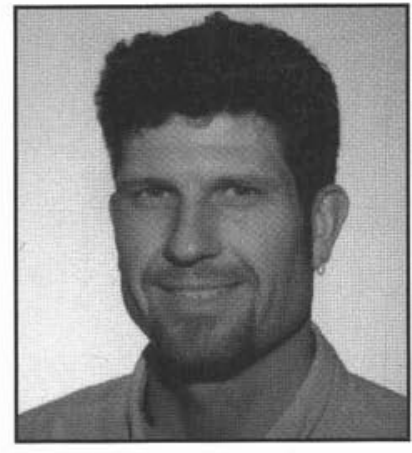

Robert D'Eon

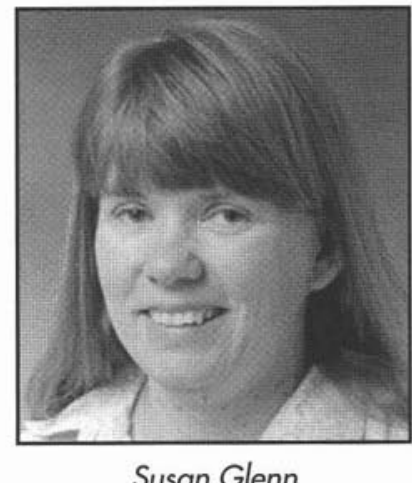

Susan Glenn
1998 (D'Eon et al. 2000). Workshop participants were given a 30-minute background lecture focusing on basic principles of landscape ecology. In particular, the issue of forest fragmentation was defined and discussed in the context of how fragmentation may affect landscape pattern. As summarized by Forman (1997), predicted changes include increases in patch number, total boundary length, habitat loss, and habitat isolation, and decreases in average patch size, total interior habitat, and connectivity. A similar exercise was delivered in February 1999 to 38 third-year undergraduate students enrolled in a Bachelor of Science program at the University of British Columbia, Department of Forest Sciences. Students were grouped into three different laboratory sessions of 10,15 , and 13 students per session and therefore treated as separate groups for analytical purposes.

Participants were shown five maps (Fig. 1) of different landscapes ranging from 3546 to 9956 ha. Maps were plotted at 1:50 000 scale and mounted on a wall side by side. Each map was plotted on a white background and contained a landscape 

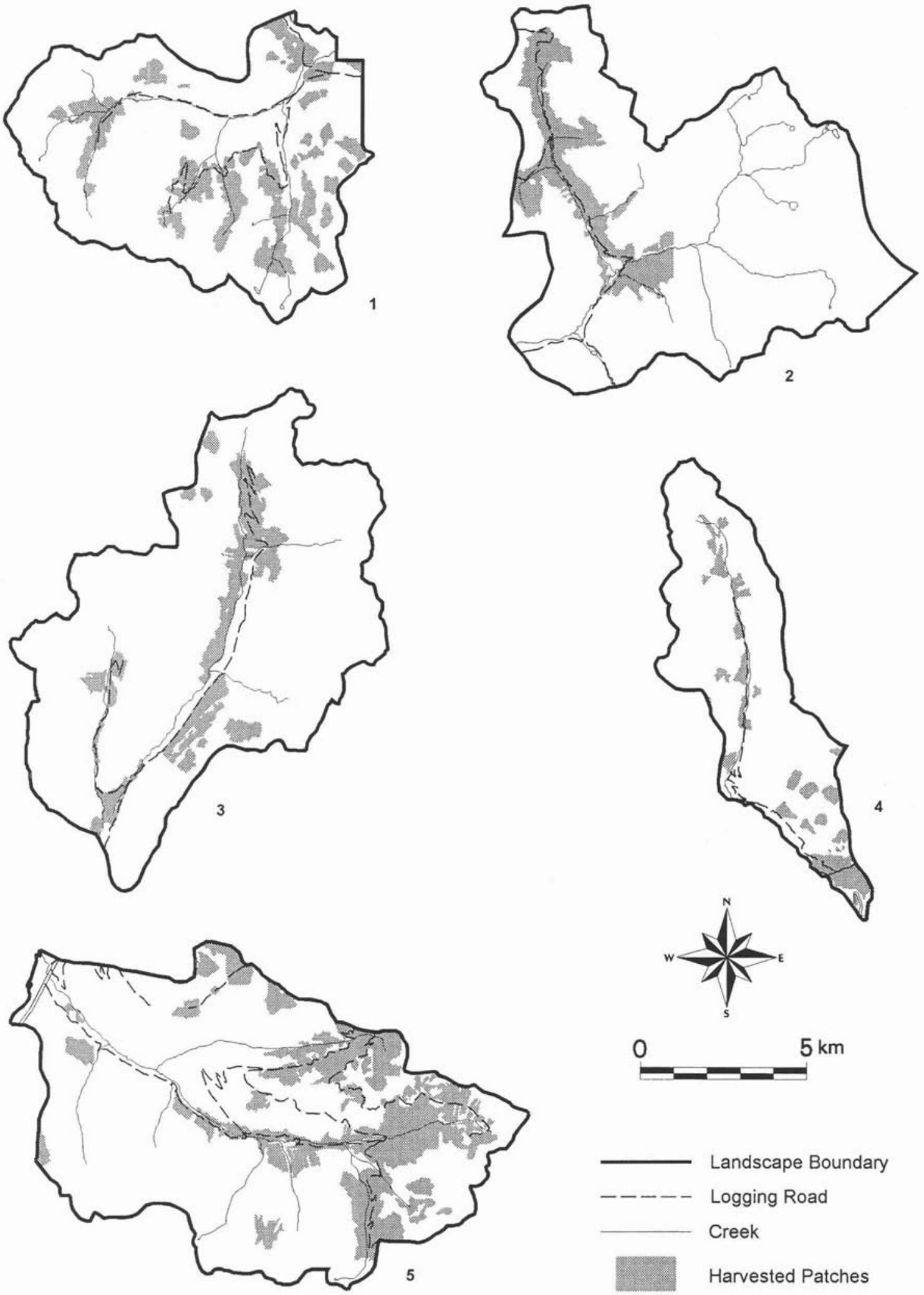

Fig. 1. Five landscapes used by workshop participants to visually and quantitatively assess landscape patterns at a professional landscape metrics workshop held in Nelson, British Columbia (D'Eon et al. 2000) and in undergraduate student laboratories (University of British Columbia, Forest Sciences Department, February 1999). Maps were in colour and plotted at 1:50 000 scale. 
boundary (determined using ecological boundaries such as heights of land) drawn as a thick black line, creeks drawn as thin blue lines, existing clear-cut harvest patches less than 40 years old shaded in brown, and logging roads indicated as thin dashed black lines (see Fig. 1). To avoid confusion between fragmentation and habitat loss effects (Fahrig 1997), landscapes were chosen on the basis of similar proportions of total patch area (range $=15$ to $24 \%$ ), but differing spatial arrangements of patches (Table 2). Landscape maps were based on forest inventory data and generally encompassed a single drainage system in steep, mountainous terrain in the Slocan Valley of southeast British Columbia $\left(49^{\circ} 42^{\prime} \mathrm{N}, 117^{\circ} 42^{\prime} \mathrm{W}\right)$. The data source for maps was British Columbia 1:20 000 provincial forest cover map series in digital format. Maps were plotted using $\mathrm{ARCINFO}^{\mathrm{TM}}$ software.

Under the assumption that existing harvest patches represent future forest spatial patterns, each participant was asked the following question for each landscape: "Is the illustrated patch pattern in this landscape fragmented?" At this point, a yes or no response by each participant was based on visual inspection of maps and personal perception and opinion. To simulate an individual manager working in relative isolation, discussion of opinions was not permitted until after responses were collected.

Following the background lecture, the remaining time was dedicated to a practical exercise where participants, working in teams of five or six people, manually (i.e., without the use of a computer) calculated the following landscape and patch indices for one assigned landscape: proportion of landscape forested (total landscape area and amount of forest land provided), number of patches, patch density (number per 100 ha of forested land), total patch area, mean patch size, total perimeter length, mean patch perimeter, total edge area (assuming $50 \mathrm{~m}$ edge effect on each side of patch perimeter), mean patch to edge area ratio, total core area (area of patch inside of $50 \mathrm{~m}$ edge effect), mean core area, mean shape index, mean fractal dimension, mean nearest neighbour (minimum edge to edge distance between patches), patch dispersion, and logging road density ( $\mathrm{km}$ per $100 \mathrm{ha}$ of forested land). Mean shape index (Patton 1975) and fractal dimension (Ripple et al. 1991) are variations of an area to perimeter ratio where 1.0 represents a perfect shape (perfect circle or straight line) and larger numbers represent increasing departure from perfect shapes and increased shape complexity. Patch dispersion (Clark and Evans 1954) is a measure of non-randomness of patch arrangement and departs from 1.0 which represents a random pattern, to $<1.0$ indicating a trend towards patch aggregation, or $>1.0$ indicating a trends towards regular or uniform spacing. Area was calculated with dot grids, linear distances were measured with scales and analogue clinometers, and arithmetic calculations were performed using hand calculators.

Following this exercise, values for each index for each landscape were posted beside the appropriate landscape map. To ensure correct values were posted, the posted values were calculated by GIS analyses prior to the workshops. Participants were then asked to review and discuss the results. In light of this newly provided quantitative data, and information and skills gained in the practical exercise, participants were again asked the same previous question of each of the same landscapes: "Is the illustrated patch pattern in this landscape fragmented?" The degree of fragmentation within a landscape was ranked
Table 1. Responses from 30 professional workshop participants (D'Eon et al. 2000) and 38 undergraduate students (Univ. British Columbia, Forest Sciences Dept., Feb. 1999) before and after a practical exercise on calculating a suite of landscape indices for 5 landscapes. The question asked: is the patch pattern illustrated in this landscape fragmented? Results indicate no significant difference between responses before and after index calculations (Wilcoxon signed rank test: $\mathrm{z}=\mathbf{- 1 . 7 4 4 ,} \mathrm{p}=\mathbf{0 . 0 8 1}$ ).

\begin{tabular}{lccc}
\hline & & \multicolumn{2}{c}{ Number of yes responses } \\
\cline { 2 - 4 } Group $^{1}$ & Landscape ${ }^{2}$ & Before & After \\
\hline Professional & 1 & 27 & 26 \\
(n=30) & 2 & 0 & 0 \\
& 3 & 5 & 2 \\
& 4 & 30 & 30 \\
Student-1 & 5 & 14 & 14 \\
(n=10) & 1 & 10 & 0 \\
& 2 & 0 & 0 \\
& 3 & 1 & 1 \\
& 4 & 10 & 10 \\
Student-2 & 5 & 8 & 0 \\
(n=15) & 1 & 15 & 14 \\
& 2 & 0 & 0 \\
& 3 & 7 & 12 \\
Student-3 & 4 & 14 & 12 \\
(n=13) & 5 & 9 & 10 \\
& 1 & 13 & 13 \\
& 2 & 0 & 0 \\
& 3 & 6 & 5 \\
Combined & 4 & 13 & 13 \\
(n=68) & 5 & 12 & 8 \\
& 1 & 65 & 53 \\
& 2 & 0 & 0 \\
& 3 & 19 & 20 \\
& 4 & 67 & 65 \\
& 5 & 43 & 32 \\
& 1 & &
\end{tabular}

${ }^{1}$ Student groups 1 to 3 signify three different laboratory sections.

${ }^{2}$ Landscapes 1 to 5 correspond to landscapes 1 to 5 in Fig. 1 .

as a function of the number of individual yes responses. In this way, the landscape with the highest number of yes responses was ranked as most fragmented. Conversely, the landscape with the lowest number of yes responses was ranked as least fragmented. Association between indices and combined group rankings was determined with Pearson correlation and differences between responses before and after index calculations were tested for statistical significance using the Wilcoxon signed rank test (Zar 1984, SPSS 1996).

\section{Results}

From combined responses, Landscape 4 was ranked as most fragmented, followed by Landscapes 1, 5, 3, and 2 in descending order of degree of fragmentation (Table 1). There was no significant difference between combined responses and rankings of fragmentation before and after calculating landscape indices (Wilcoxon signed rank test: $\mathrm{z}=-1.744, \mathrm{p}=0.081$; Table 1). Pearson correlation analyses revealed highly significant associations between number of patches $(r=0.944)$, patch density $(\mathrm{r}=0.937)$, and patch shape $(-0.907)$, and fragmentation rankings (all $P<0.05$; Table 2). Landscape 2 had the lowest number of patches, lowest patch density, and highest shape index, and was therefore consistently perceived to be not fragmented (Table 2). Conversely, landscapes 4 and 1 had the highest number of patches, highest patch densities, and lowest shape indices, and were consistently perceived to be fragmented. The 
Table 2. Landscape indices for landscapes used in a professional landscape metrics workshop (D'Eon et al. 2000) and student laboratories (University of British Columbia, Forest Sciences Department, February 1999) for comparison with intuitive human perceptions of landscape pattern.

\begin{tabular}{|c|c|c|c|c|c|c|}
\hline \multirow[b]{2}{*}{ Landscape Index ${ }^{1}$} & \multirow[b]{2}{*}{$\begin{array}{l}\text { Correlation } \\
\text { with rank }\end{array}$} & \multicolumn{5}{|c|}{ Landscape $^{3}$} \\
\hline & & $\begin{array}{c}1 \\
(2)\end{array}$ & $\underset{(5)}{2}$ & $\begin{array}{c}3 \\
(4)\end{array}$ & $\begin{array}{c}4 \\
(1)\end{array}$ & $\begin{array}{c}5 \\
(3)\end{array}$ \\
\hline Total landscape area (ha) & -0.793 & 6513 & 8755 & 8980 & 3546 & 9956 \\
\hline Total forested area (ha) & -0.257 & 5007 & 4439 & 5591 & 2803 & 9238 \\
\hline Number of patches & $0.944 *$ & 28 & 4 & 12 & 29 & 25 \\
\hline Patch density (\#/100 ha) & $0.937 *$ & 0.56 & 0.09 & 0.21 & 1.03 & 0.27 \\
\hline$\%$ of forest in patch type & -0.279 & 24 & 22 & 17 & 15 & 23 \\
\hline Total patch area (ha) & -0.204 & 1203 & 959 & 922 & 423 & 2096 \\
\hline Mean patch size (ha) & -0.704 & 43.0 & 239.8 & 15.1 & 14.6 & 48.9 \\
\hline Total patch perimeter (m) & 0.405 & 97507 & 49300 & 13708 & 48356 & 26257 \\
\hline Mean patch perimeter $(\mathrm{m})$ & -0.693 & 3482 & 12325 & 1714 & 1667 & 3282 \\
\hline Total edge area (ha) & 0.405 & 947 & 474 & 132 & 466 & 251 \\
\hline Mean edge to patch area ratio & 0.537 & 0.79 & 0.49 & 1.09 & 1.10 & 0.64 \\
\hline Total patch core area (ha) & -0.166 & 751 & 724 & 63 & 216 & 273 \\
\hline Mean patch core area (ha) & -0.719 & 27.8 & 181.0 & 12.6 & 9.8 & 39.0 \\
\hline Mean patch shape index & $-0.907 *$ & 1.52 & 2.31 & 2.06 & 1.50 & 1.53 \\
\hline Mean patch fractal dimension & -0.350 & 1.27 & 1.31 & 1.45 & 1.32 & 1.28 \\
\hline Mean nearest neighbour (m) & -0.162 & 165 & 30 & 624 & 139 & 113 \\
\hline Patch dispersion & 0.205 & 0.22 & 0.01 & 0.47 & 0.25 & 0.08 \\
\hline Log road density (km/100 ha) & 0.766 & 1.34 & 0.56 & 0.40 & 1.09 & 0.50 \\
\hline
\end{tabular}

${ }^{1}$ Densities based on total forested area; edge and core area calculated by assuming $50 \mathrm{~m}$ edge effect on either side of patch perimeter; shape index from Patton (1975); fractal dimension calculation from Ripple et al. (1991); patch dispersion index from Clark and Evans (1954).

${ }^{2}$ Pearson correlation coefficient between combined group rankings and landscape index values. High coefficients signify high association between an index and the degree of fragmentation as determined by survey participants. Significance indicated $(*)$ at $\propto=0.05$.

${ }^{3}$ Landscapes 1 to 5 correspond to landscapes 1 to 5 in Fig. 1. Number in brackets is combined ranking of degree of fragmentation $(1=$ most fragmented, $5=$ least fragmented).

remaining three landscapes had index values ranging between these extremes, and resulted in mixed perceptions of fragmentation among and within groups (Table 1).

In four cases (out of 150 individual response pairs), within the professional workshop, a participant changed their response between the first and second time of questioning (Table 1). All 30 workshop participants worked in a forest resource professional capacity within Canada, with 26 located within British Columbia. Two participants worked in Alberta, 1 in Ontario, and the remaining person in the Yukon Territory. By working sector, 11 worked within the industrial sector (e.g., forest licensee), nine government, eight forestry consulting, and the remaining two the academic sector. Within the student laboratories, 32 cases (out of 190 individual responses pairs) occurred where a student changed their initial response; a significantly higher proportion than that within the professional workshop (chi-square $=17.79, \mathrm{p}<0.001$ ). All participants (professional and student combined) had some previous exposure to basic principles of landscape ecology, but no one considered themselves to have advanced knowledge of the subject.

\section{Discussion}

In this study, landscapes associated with extreme index values (i.e., smallest or largest value of the five landscapes for a given index) tended to be consistently perceived as either fragmented or not, before and after calculating indices. This is especially true when considering the number of patches, patch density (function of number of patches), and patch shape. This suggests that these very apparent and easily visualized parameters may tend to overshadow other less-obvious parameters. It also suggests that a landscape dominated by a high number of regularly shaped (e.g., rectangular) harvest blocks was highly associated with what survey participants believe fragmentation to be.

The finding that conclusions about fragmentation generally remained unchanged from initial intuitive perceptions implies that either landscape indices provided little additional information, so that enough information can be collected intuitively to make a correct decision on fragmentation, or what we perceive and call fragmentation is different from what landscape indices measure. In either case, this implies that the current usefulness of landscape indices in helping to define and quantify central concepts in landscape ecology is limited.

This situation is perhaps due to a lack of construct validity in landscape metrics work. Construct validity, a concept commonly used in psychology research, concerns the extent to which a test (or landscape metric in this case) measures what its users claim it measures (Johnstone et al. 1997, Chow 1998, Taub 1998). Use of the hundreds of available landscape metrics is often unaccompanied by an explicit description of what each metric measures relative to ecological process. The ecological relevance of landscape metrics in these cases is unclear and left to interpretation. Do we use a landscape metric simply because it is measurable and the data are available, or because it measures what concerns us, in this case fragmentation? This question poses a challenge to clearly define the ecological relevance of landscape metrics in applied ecology work.

We do not suggest that the use of landscape metrics is invalid. There are several good examples of the use of landscape metrics in investigating trends and relationships in landscape pattern (Franklin and Forman 1987, Ripple et al. 1991, McGarigal and McComb 1995, Garrabou et al. 1998). Indeed, establishing trends in landscape patterns through time may be the best utility of landscape metrics at present. However, as quantitative measures of absolute landscape structure relative 
to ecological process, much more work is required (Carey et al. 1992, Schumaker 1996, Davidson 1998).

From an alternative view, the usefulness of landscape indices may not lie in providing a quantitative scale of things such as fragmentation, but rather in providing a means of adjusting the way we view and define them. They may also help us identify our biases in what we perceive as valuable and desirable in landscapes. Ahl and Allen (1996) in discussions of hierarchy theory state that definitions in science are not true or false, but are only more or less useful. They view definitions as a product of an observer's search given a particular intent and perspective (Ahl and Allen 1996). They identify two types of definitional entities: those postulated prior to observation, and those derived or modified after empirical observation. In this way, landscape indices can provide useful information in modifying criteria for future work on fragmentation. In this study for example, perceptions of fragmentation were highly associated with number of patches, patch density, and patch shape; suggesting that these particular indices reflect important human values that may be useful in defining landscape structure. However, more work is required to establish the relative roles of human values and ecological significance in the use of landscape indices.

Differences in personal experience may also play a role in how landscape patterns are perceived. In this study students were over seven times more likely (odds ratio $=7.4, \ln$ (odds) $=2 \pm 1.086$; SPSS 1996) to change their perception of landscape fragmentation before and after calculating indices. Only 4/150 professional responses versus $32 / 190$ student responses changed after calculating landscape indices. We suggest this is due to stronger-held beliefs and opinions held by professionals with more management exposure and experience.

Finally, human perception and cultural values can structure landscapes through landscape management goals based on perception and intuition (Nassauer 1997). In turn, changes in cultural values can result in changes in landscape structure. A good example of this is a historic shift among wildlife ecologists from viewing forest edges as generally beneficial (Leopold 1933) to viewing them as detrimental to many species (e.g., Yahner and Mahan 1996, Harris 1988,). This has no doubt contributed to a recent shift in North American forest practices away from small, dispersed openings (Franklin and Forman 1987) to a pattern incorporating larger opening sizes (e.g., Province of British Columbia 1996). This landscape management by perception paradigm is enhanced, if not driven by a lack of reliable quantitative measures of landscape structure. As a result of our inability to quantify central concepts such as fragmentation and connectivity, intuitive human perception will likely continue to have a large influence on management of landscape structure and pattern.

\section{Acknowledgements}

We thank Slocan Forest Products (Slocan Division), Kokanee Forests Consulting, and the University of British Columbia for providing logistical support and equipment to conduct a workshop on landscape metrics. Graduate student support was provided to R. D'Eon by the University of British Columbia Forest Sciences Department, the National Science and Engineering Research Council of Canada, and a Canfor Corporation fellowship in forest wildlife management. D. Mack (Cave Creek Systems, Nelson, BC) performed all GIS and map work. J.P. Kimmins and S. Sheppard (University of British Columbia, Forest Science Department) and an anonymous reviewer provided very helpful reviews of earlier drafts. Most of all we are grateful to workshop participants and students in the Forests Sciences Department, University of British Columbia for their cooperation and willingness to participate.

\section{References}

Ahl, V. and Allen, T.F. 1996. Hierarchy theory: a vision, vocabulary, and epistemology. Columbia University Press, New York, NY. 205 p.

Carey, A.B., S.P. Horton and B.L. Biswell. 1992. Northern spotted owls: influence of prey base and landscape character. Ecol. Monographs 62: 223-250.

Chow, S.L. 1998. In defense of the construct validity approach. Theory and Psychology. 8: 481-487.

Clark, P. J. and F.C. Evans. 1954. Distance to nearest neighbour as a measure of spatial relationships in populations. Ecology 35: 445-453. Davidson, C. 1998. Issues in measuring landscape fragmentation. Wildl. Soc. Bull. 26: 32-37.

D'Eon, R.G., J.A. Johnson and E.A. Ferguson. 2000. Ecosystem management of forested landscapes: directions and implementation. Proceedings of a conference held 26-28 October, 1998, Nelson, British Columbia. Printed and distributed by UBC Press, Vancouver, BC. Fahrig, L. 1997. Relative effects of habitat loss and fragmentation on population extinction. J. Wildl. Manage. 61: 603-610.

Forman, R.T. 1997. Land mosaics. The ecology of landscapes and regions. Cambridge University Press. 632 p.

Franklin, J. F. and R.T. Forman. 1987. Creating landscape patterns by forest cutting: ecological consequences and principles. Landscape Ecol. 1: 5-18.

Garrabou, J., J. Riera and M. Zabala. 1998. Landscape pattern indices applied to Mediterranean subtidal rocky benthic communities. Landscape Ecol. 13: 225-247.

Gustafson, E.J. 1998. Quantifying landscape spatial pattern: what is the state of the art? Ecosystems 1: 143-156.

Hargis, C.D., J.A. Bissonette and J.L. David. 1998. The behavior of landscape metrics commonly used in the study of habitat fragmentation. Landscape Ecol. 13: 167-186.

Harris, L. D. 1988. Edge effects and conservation of biotic diversity. Cons. Bio. 2: 330-332.

Hulshoff, R.M. 1995. Landscape indices describing a Dutch landscape. Landscape Ecol. 10: 101-111.

Johnstone, B., D. Holland and J.E. Hewett. 1997. The construct validity of the category test: is it a measure of reasoning or intelligence? Psychological Assessment 9: 28-33.

Leopold, A. 1933. Game management. Charles Scribner and Sons, New York, NY. 481 p.

McGarigal, K. and W.C. McComb. 1995. Relationships between landscape structure and breeding birds in the Oregon coast range. Ecol. Monographs 65: 235-260.

Nassauer, J.I. 1988. The aesthetics of horticulture: neatness as a form of care. HortScience 23: 973-977.

Nassauer, J. I. 1995a. Culture and changing landscape structure. Landscape Ecol. 10: 229-237.

Nassauer, J.I. 1995b. Messy ecosystems, orderly frames. Landscape J. 14: 161-170.

Nassauer, J.I. 1997. Placing nature: culture and landscape ecology. Island Press, Washington, DC. 179 p.

Patton, D.R. 1975. A diversity index for quantifying habitat "edge." Wildl. Soc. Bull. 3: 171-173.

Province of British Columbia. 1996. Forest practices code of British Columbia act. Revised statutes of British Columbia, chapter 159.

Ripple, W., G. Bradshaw and T. Spies. 1991. Measuring forest landscape patterns in the Cascade range of Oregon, U.S.A. Cons. Biol. 57: 73-88. 
Schumaker, N. 1996. Using landscape indices to predict habitat connectivity. Ecology 77: 1210-1225.

SPSS. 1996. SYSTAT ${ }^{\circledR} 7.0$ for windows. SPSS Inc. Chicago, IL. Taub, J.M. 1998. Eysenck's descriptive and biological theory of per- sonality: a review of construct validity. Int. J. Neuroscience. 94: 145-197. Yahner, R. and Mahan, C. 1996. Depredation of artificial ground nests in a managed, forested landscape. Cons. Biol. 10: 285-288.

Zar, J.H. 1984. Biostatistical analysis. Prentice-Hall Inc., Englewood 